\title{
A RESEARCH ON THE EFFECT OF ORGANIZATIONAL SAFETY CLIMATE UPON THE SAFE BEHAVIORS
}

\author{
Assoc. Prof. Dr. Ömer Sadullah, İstanbul University, Faculty of Business \\ Administration, omersad@gmail.com \\ Dr. Selahattin Kanten, Çanakkale Onsekiz Mart University, Gelibolu Piri Reis \\ Vocational School, kanten286@hotmail.com
}

\begin{abstract}
This study aims to investigate the relationship between the organizational safety climate and the safety behaviors of the employees. It is been accepted by many researchers that unsafe employee behavior at work place is one of the primary determinants of occupational accidents. More recently researchers suggest that safe/unsafe behaviors of the employees are affected by certain organizational factors. Recent studies accept organizational safety climate as one these factors that affects safe/unsafe behaviors of the employees. In this context, this study conducted in an active shipyard in Turkey, finds that there are significant relations between the four dimensions of the organizational safety climate and the safety behavior of the employees.
\end{abstract}

Key Words: Job safety climate, safe behavior

\section{INTRODUCTION}

Occupational safety aims to prevent the accidents caused by the unsafe behavior of the employees and/or the unsafe work environment, and to create a safe working environment. While the goal of employee health is to protect employees against risks and health hazards inherent in their jobs. In other words keeping the health of the employees from detoriating because of the jobs they have do is the main purpose employee health dimension (Sadullah, 2008: 514). In order for the safety and health function to be effective, among other factors, organizational climate that supports and encourages employees to exhibit the behavior, either individually or collectively, required by safety procedures is another important factor. This required behavior generally 
comprises the following of established safety procedures, standards and usage of personal protective equipment (Neal and Griffin, 2006: 947). Research points out that, occupational accidents are the result of random combination of many factors found in the workplace. Generally the causes of occupational accidents are classified as unsafe conditions and unsafe behaviors. Some studies reveal that organizational and social factors are not to be overlooked because these factors influence safety behaviors (Choudhry and Fang, 2008: 567-568). Recent research findings tie the majority of the workplace accidents and injuries to unsafe behavior of the employees rather than unsafe work environment (Mullen, 2004: 275). Empirical research looked for the affects of organizational safety climate upon the safety behavior of the employees (Glendon and Litherland, 2001; Seo, 2005; Neal and Griffin, 2006; Johnson, 2007; Zhou et al., 2008; Mohamed et al., 2009). These studies accept that the safety climate of the organization affects the safe/unsafe behavior of the employees in the workplace. As a long time recognized, important and multifaceted factor in organizations, safety climate can be described as the employees shared perceptions of the importance and the priority of the safety together with the safety policies, practices and applications in the workplace (Vinodkumar and Bhasi, 2009: 659). The purpose of this study therefore is determined in this context to investigate the affect of the organizational safety climate upon the safety behavior of the employees.

\section{JOB SAFETY CLIMATE AND SAFETY BEHAVIOR RELATIONSHIP}

Studies in this field generally accept that the majority of the occupational accidents occur as a consequence of the unsafe behavior of the employees. The results of the completed studies also point out that safe/unsafe behaviors of the employees are influenced by certain organizational and cultural factors (Tomas et al., 1999; Brown et al., 2000; Oliver et al., 2002; Mullen, 2004: 275 ). Safety culture, as one these factors, reprsents the individuals' shared beliefs, values, attitudes and behaviors about safety in the workplace while safety climate is 'a snapshot of the state of safety providing an indicator of the underlying safety culture of a work group, plant or organization". Although both concepts have a theoretical basis, safety climate appears the preferred term when psychometric measurement is involved (Seo, 2005: 190). According to the researchers safety climate is a temporal measure of culture, focusing perceptions, values and attitudes at a particular time. Thus, safety climate is regarded as manifestation of safety culture in the behavior and expressed attitude of employees (Cheyne et al., 2002: 651; Mearns et al., 2003: 642).

The safety climate literature has examined the link between safety climate and safety outcomes, such as compliance with safe working practices and accidents. A large number of studies have demonstrated that perceptions of safety climate are positively correlated with safety behaviors (Neal and Griffin, 2006: 946). Dov (2008), support that; "the discussion above offers an explicit 
account for the reported relationships between safety climate and behavior, which is often missing in the extant literature. Namely, by construing the true priorities among competing facets as the primary target of climate perceptions, it follows that they indicate probable consequences of alternative role behaviors (e.g., stressing speed over safety), informing behavior-outcome expectancies. Such expectancies have been shown to provide the strongest prediction of actual behavior presenting the rationale for a positive relationship between safety climate and safety behavior (Dov,2008: $377-378$ ).

Safety climate is a concept that can be seen as the current surface features of a safety culture, which are discerned from the employees' attitudes and perceptions (Zhou et al., 2008: 1407). Measuring safety climate can be compared to taking the "safety temperature" of an organization, which provides a snapshot of that organization's "state of safety" at a discrete point in time. Researchers (Cox and Cox, 1991; Donald and Canter, 1994; Niskanen, 1994; Coyle et al. 1995; Varonen and Mattila, 2000; Glendon and Litherland, 2001; Seo, 2005; Clarke, 2006; Johnson, 2007; Turnberg and Daniel, 2008) measured safety climate using scales which covered the various dimensions (personal protective equipment, policies and practices, safety related condition, risk justification, communication, management support, safety training, motivation safety knowledge, etc.). On the other hand there is no agreement about the number of dimensions and factorial structure within the present studies. Some these empirical studies accept that there is a significant relationship between the safety climate and the safety behavior of the employees (Glendon and Litherland, 2001; Mohamed, 2002; Mullen, 2004; Clarke, 2006; Seo,2005; Johnson, 2007; Mohamed et al., 2009). However there are few studies where the validity of the factorial structure of safety climate is tested and effects of safety climate factors upon the safety behavior of employees studied. Therefore in order to test the relationship between the dimensions of the safety climate and the safety behavior hypothesis shown below is developed.

$\mathrm{H} 1$ : There is a statistically significant relationship between the dimensions of the safety climate and the safety behaviors.

\section{RESEARCH METHODOLOGY}

\subsection{Sample and Procedure}

This study is conducted in a large sized Turkish shipyard. The high managements of two shipyard enterprises were approached for permission to conduct research on premises and permission was obtained from one. Therefore from the 200 questionnaires that were sent, 147 (\%73) were returned and 125 (\%62) were accepted as valid and included in the evaluations. \%70 of the employees whose responses were included in the evaluation is under the age 32. \%49 of the employees completed only primary education, \% 44 graduated from highshools (Lycéé). \%40 employees worked more than four 
years in this shipyard. $\% 28$ of the employees reported that they had experienced occupational accidents while $\% 42$ reported they had close calls.

\subsection{Measures}

Questionnaire survey method is used for data obtainment. Questionnaire form contains 59 statements related to measure safety climate and safety behaviors. All items were measured on a 5-point rating scale ranging from 1 (strongly disagree) to 5 (strongly agree). Forty three of the statements were taken from the scale used by Glendon and Litherland (2001) in their study and translated into Turkish. Sixteen statements related to the safety behaviors were taken from the studies of Seo (2005) and Størseth'in (2006) and adapted to Turkish. Questionnaire also contains seven questions to determine demographic characteristics of the employees.

\subsection{Statistical Analyses}

SPSS for Windows 11.5 program is used to analyze the data obtained by the questionnaire survey. Factor analysis is used with the variables related to safety climate and the structural validity of the safety climate dimensions was tested. Cronbach Alpha values to determine the reliability levels of the scales were computed. Multiple regression analysis is used to explain the relationship between the dimensions of the safety climate and the safety behaviors of the employees.

\section{RESULTS}

\subsection{Structure of Safety Climate}

The procedure adopted for identifying the structure of the Safety climate and the reliability analysis for the study are presented below.

\subsubsection{Factor Analysis}

Kaiser-Meyer-Olkin (KMO) test that is used for basic components analysis for the safety climate variables showed that the size of the sample was sufficient (KMO value ,865) for factor analysis. Barlett test conducted to determine whether the data for safety climate conformed to normal distribution or not produced a significant result $(3915,092 ; p<0,01)$. Through factor analysis of the safety climate variables and Varimax Rotationed Factor Loadings, 9 factors obtained with self values greater than 1.00 . These factors explain the $\% 73.035$ of the total variance. Three items with a factor load under 0.40 were excluded from the scale. It can be seen that the remaining 40 items are grouped under the relevant factors as per theoretical structure. It can be said that the scales used, can measure a single structure that complies with the theory and have 
structural validity. The 9 factors with their names, items in each factor, their factor loadings, explained variance and reliability coefficients are presented in Table 1.

\subsection{Reliability Analyses}

Out of various methods used for measuring reliability, the internal consistency method is considered to be the most effective method, especially in field studies (Vinodkumar and Bhasi, 2009: 61). The internal consistency coefficients (Cronbach's Alpha) of the nine factors that comprise the safety climate are as follows: $0.88 ; 0.87 ; 0.87 ; 0.86 ; 0.83 ; 0.80 ; 0.74 ; 0.83$ and 0.85 '. Computed internal consistency coefficient for all forty items is 0.95 . Internal consistency coefficient for all 16 items that measure the safety behaviors of the employees is computed also as 0.85 . These results show that the scales used in this study have sufficient reliability for social sciences.

\section{Tablo1: Varimax Rotated Factor Loadings for Nine-Factor Solution}

Factor 1: Adequacy \& sufficiency of procedures and investigations (variance $=12,863 \%$, Cronbach's. Alpha= 0.88)

1.Technical correctness of work procedures and activities

2.Written documents are comprehensible and complete

3.A systematic process is used to identify which jobs and tasks have the greatest

priority with regard to the development of procedures

4.Investigation and research systems are periodically updated

5 . Access to every document because of an efficient documentation system

6. Every incident is investigated by trained and experienced personnel

7.Written procedures fit exactly with actual practices

Factor 2: Labor-management relations $(10,142 \%, 0.87)$

8.Employees confidence of management

9.Good working relations

0.693

10.Management trust in employees

0.691

11.Employees' confidence about their future in the workplace

0.610

12. High morale of the employees

0.607

13.Encouraging employees to look each after (buddy system)

0.597

14.Effective communication of company policies to employees

Factor 3: Communication (9,003\%, 0.87)

15.Consulting with employees concerning changes about work arrangements

16.Employees' ease of discussing important plans

17. Open discussion of problems between supervisors and workers

18.Adequate rights provided to personnel to talk about problems

0.753

Factor 4: Safety and PPE use training $(8,961 \%, 0.86)$

19. Explanation of the changes in practices and their effect upon safety

20.Explanation of the changes in the work environment

21. Task and equipment specisific training provided to individual employees 
23. Encouragement to use PPE

24.Definning probable risks and dangers during training

Factor 5: Absence of workpressure $(7,450 \%, 0.83)$

25.Presence of sufficient personnel to carry out the work load $\quad 0.745$

26.Employees having sufficient time to complete the tasks 0.726

27. Realistic project time schedules

28.Sufficient thinking time provided for employees for planning and carry out their work to an adeqate standard

Factor 6: Control of work load increases $(7,044 \%, 0.80)$

29 .Safely meeting the requirements of sudden work load surges

30.Balanced and reasonable work load

31.Not disregarding safety rules when solving problems associated

Factor7: Training functionality $(6,123 \%, 0.74)$

32.Training covering the skills required in emergencies

33. Training given by individuals with relavant operational

experience about the subject

34.Preventing employees to work alone

Factor 8: General safety $(5,855 \%, 0.83)$

35.Implementation of safety rules without disrupting the established work practices

Factor 9: Maintenance and spares $(5,504 \%, 0.85)$

38.Obtainment of spare parts within acceptable time periods

\subsection{Multiple Regression Analysis}

Multiple regression analysis was conducted to evaluate the relationship between the safety behaviors and the safety climate factors. Results of this analysis are summarized in table 2 to show which factors influenced the safety behaviors. As can be seen from table $2 \% 38$ of the created variability of the employee safety behaviors is explained by the four factors of the safety climate. At 0.000 level computed $F$ value is $(p<0.001)$. Correlation between the dependent and independent variables are statistically significant. Four factors of the safety climate influence the safety behaviors of the employees. Findings of the multiple regression analysis support the primary Hypothesis of the study. Increase in the independent variables with positive $\beta$ values cause an increase in the same direction with the dependent variable. Safety climate factors that most influenced the safety behaviors positively were "safety and PPE use training" ( $\beta=0.466, p<0.001)$; "absence of work pressures" $(\beta=0.323, p<0.001)$; "maintenance \& spares" $(\beta=0.270, p<0.001)$. Communication factor which has negative beta value $(\beta=-0.220, p<0.001)$ seems to have an inverse correlation with the safety behaviors. So it may said that an increase in the employees' perception of communication causes a decrease in their safety behavior. 
Tablo 2: Effects of Safety Climate Upon Safety Behaviors

\begin{tabular}{|c|c|c|c|c|}
\hline & $\mathrm{R}^{2}$ & $\mathrm{~F}$ & $\beta$ & $\mathrm{p}$ \\
\hline Safety Climate & .38 & 23.144 & & 0.000 \\
\hline \multicolumn{2}{|c|}{ Safety and PPE use training } & & .466 & 0.000 \\
\hline \multicolumn{2}{|c|}{ Absence of work pressures } & & .323 & 0.000 \\
\hline \multicolumn{2}{|c|}{ Maintenance \& spares } & & .270 & 0.000 \\
\hline \multicolumn{2}{|c|}{ Communication } & & -.220 & 0.000 \\
\hline
\end{tabular}

\section{CONCLUSION}

This study aimed to explain the correlation between the safety climate and the safety behaviors of the employees has found empirical evidence that supports the study's hypothesis. With factor analysis, conducted before the regression analysis, factor structure validity of the safety climate scale and the reliability levels of all scales were tested. The regression analysis to determine the influence of nine safety climate factors upon safety behaviors revealed that four factors influenced the safety behaviors. It can be said that "safety and PPE use training", "absence of work pressures", "maintenance \& spares" factors influenced the safety behaviors positively. On the other hand "communication" factor had a negative influence upon the safety behavior. This finding might be the result of the employee's negative perceptions of communication factor. Inefficient communication practices or lack of effective communication systems might have caused the employees to be dissatisfied and have negative perceptions. We also mentioned that the questionnaire contained seven questions to determine demographic characteristics of the employees. Because of the time constraints these were not used in the analyses.

As we mentioned above this study was conducted in a shipyard but we have to also point out that this shipyard is privately owned company and located at Gelibolu. To determine the state of the safety performance of privately owned shipyards, especially those concentrated at Tuzla region in İstanbul does not require a study because the frequency of accidents that involve the loss of lives can be followed in the media. On the other hand we should also point out that there also state owned shipyards operated by Turkish Navy. The number of accident free days is posted at gates and one of the authors of this study can testify that this number increased without a pause for well over period of more than a year. This picture may provide a clue about the state of the safety climate that exists in privately and state owned shipyards. Of course we recommend a study in this direction to verify whether a different state of safety climates exists between privately owned and state owned shipyards.

Even though these findings are specific to the company where this study is conducted we believe that they are still important because they provide evidence that four dimensions of safety climate could directly influence the 
safety behaviors of the employees. We also believe that this study, according to our knowledge, is the first of its kind to investigate the concept of safety climate in Turkey. From the perspective of HRM it is the responsibility of this function to create a safety climate that encourages employees to exhibit proper behaviors consistent with safety. Unfortunately effective HRM is one the weak links in the Turkish management scene. We hope that this study will be stepping stone and iead for more refined and comprehensive studies in the future and enhance the urgently needed effectiveness of HRM in Turkey.

\section{REFERENCES}

BROWN, K.A., WILLIS, P.G. and PRUSSIA, G.E. (2000): "Predicting Safe Employee Behavior in The Steel Industry: Development and Test of A Sociotechnical Model", Journal of Operations Management, 18: 445-465.

CHEYNE, A., OLIVER, A., TOMAS, J.M. and COX, S. (2003): "The Architecture of Employee Attitudes to Safety In The Manufacturing Sector", Personnel Review, 31: 649-670.

CHOUDHRY, R.M. and FANG, D. (2008): "Why Operatives Engage in Unsafe Work Behavior: Investigating Factors on Construction Sites", Safety Science, 46: 566-584.

CLARKE, S. (2006): "Safety Climate in An Automobile Manufacturing Plant. The Effects of Work Environment, Job Communication and Safety Attitudes on Accidents and Unsafe Behaviour", Personnel Review, 35: 413-430.

COX, S. and COX, T. (1991): "The Structure of Employee Attitudes to Safety: A European Example", Work and Stres, 5: 93-106.

COYLE, I.R., SLEEMAN, S.D. and ADAMS, N. (1995): "Safety Climate. Journal of Safety Research, 26: 247-254.

DONALD, I. and CANTER, D. (1994): "Employee Attitudes and Safety in Chemical Industry", Journal of Loss Prevention in Process Industries, 7: 203208.

DOV, Z. (2008): "Safety Climate and Beyond: A Multi-Level Multi-Climate Framework", Safety Science, 46: 376-387.

GLENDON, A.I, and LITHERLAND, D.K. (2001): "Safety climate Factors, Group Differences and Safety Behaviour in Road Construction", Safety Science, 39: 157-188.

JOHNSON, S.E. (2007): "The Predictive Validity of Safety Climate", Journal of Safety Research, 38: 511-521. 
MEARNS, K., WHITAKER, S.M. and FLIN, R. (2003): "Safety Climate, Safety Management Practice and Safety Performance in Offshore Environments", Safety Science, 41: 641-680.

MOHAMED, S. (2002): "Safety climate in construction site environments", Journal of Construction Engineering and Management, 5: 375-384.

MOHAMED, S., ALI, T.H. and Tam, W.Y.V. (2009): "National Culture and Safe Work Behaviour of Construction Workers in Pakistan", Safety Science, 47: 2935.

MULLEN, J. (2004): "Investigating Factors that Influence Individual Safety Behavior at Work", Journal of Safety Research, 35: 275- 285.

NEAL, A. and GRIFFIN, M.A. (2006): "A Study of The Lagged Relationships Among Safety Climate, Safety Motivation, Safety Behavior, and Accidents at the Individual and Group Levels", Journal of Applied Psychology, 91: 946-953.

NISKANEN, T. (1994): "Safety climate in the road administration", Safety Science, 17: 237-255.

OLIVER, A., CHEYNE, A., TOMAS, J.M. and COX, S. (2002): "The Effects of Organizational and Individual Factors on Occupational Accidents", Journal of Occupational and Organizational Psychology, 75: 473-488.

SADULLAH, O. (2008): "İnsan Kaynakları Yönetiminde Koruma İşlevi (İşgüvenliği ve İşgören Sağlığı)", Sadullah et all. (eds.) İnsan Kaynakları Yönetimi 3rd Edition, İstanbul, İşletme Fakültesi Review

SEO, D.C. (2005): "An Explicative Model of Unsafe Work Behavior", Safety Science, 43: 187-211.

TOMAS, J.M., MELIA, J.L. and OLIVER, A. (1999): "A Cross-Validation of A Structural Equation Model of Accidents: Organizational and Psychological Variables As Predictors of Work Safety", Work \& Stress, 13: 49-58.

TURNBERG, W. and DANIELL, W. (2008): "Evaluation of A Healthcare Safety Climate Measurement Tool”, Journal of Safety Research, 39: 563-568.

VARONEN, U. And MATTILA, M. (2000): "The Safety Climate and It's Relationships to Safety Practices, Safety of Work Environment and Occupational Accidents in Eight Wood-Processing Companies", Accident Analysis and Prevention, 32: 761-769.

VINODKUMAR, M.N. and BHASI, M. (2009): "Safety Climate Factors and Its Relationship With Accidents and Personal Attributes in The Chemical Industry", Safety Science, 47: 659-667. 
ZHOU, Q., FANG, D. and WANG, X. (2008): "A Method to Identify Strategies for The Improvement of Human Safety Behavior by Considering Safety Climate and Personal Experience", Safety Science, 46: 1406-1419. 